\title{
Predicting the profile of nutrients available for absorption: from nutrient requirement to animal response and environmental impact
}

\author{
J. Dijkstra ${ }^{1 \dagger}$, E. Kebreab² ${ }^{2}$ J. A. N. Mills ${ }^{3}$, W. F. Pellikaan ${ }^{1}$, S. López ${ }^{4}$, A. Bannink ${ }^{5}$ \\ and J. France ${ }^{2}$ \\ ${ }^{1}$ Animal Nutrition Group, Wageningen Institute of Animal Sciences, Wageningen University, Marijkeweg 40, 6709 PG Wageningen, The Netherlands; ${ }^{2}$ Centre for \\ Nutrition Modelling, Department of Animal and Poultry Science, University of Guelph, Guelph, Ontario N1G 2W1, Canada; ${ }^{3}$ School of Agriculture, Policy and \\ Development, University of Reading, Earley Gate, Reading RG6 6AR, UK; ${ }^{4}$ Department of Animal Production, University of Leon, 24007 Leon, Spain; ${ }^{5}$ Animal \\ Sciences Group, Division Animal Production, Wageningen University and Research Centre, PO Box 65, 8200 AB Lelystad, The Netherlands
}

Current feed evaluation systems for dairy cattle aim to match nutrient requirements with nutrient intake at pre-defined production levels. These systems were not developed to address, and are not suitable to predict, the responses to dietary changes in terms of production level and product composition, excretion of nutrients to the environment, and nutrition related disorders. The change from a requirement to a response system to meet the needs of various stakeholders requires prediction of the profile of absorbed nutrients and its subsequent utilisation for various purposes. This contribution examines the challenges to predicting the profile of nutrients available for absorption in dairy cattle and provides guidelines for further improved prediction with regard to animal production responses and environmental pollution.

The profile of nutrients available for absorption comprises volatile fatty acids, long-chain fatty acids, amino acids and glucose. Thus the importance of processes in the reticulo-rumen is obvious. Much research into rumen fermentation is aimed at determination of substrate degradation rates. Quantitative knowledge on rates of passage of nutrients out of the rumen is rather limited compared with that on degradation rates, and thus should be an important theme in future research. Current systems largely ignore microbial metabolic variation, and extant mechanistic models of rumen fermentation give only limited attention to explicit representation of microbial metabolic activity. Recent molecular techniques indicate that knowledge on the presence and activity of various microbial species is far from complete. Such techniques may give a wealth of information, but to include such findings in systems predicting the nutrient profile requires close collaboration between molecular scientists and mathematical modellers on interpreting and evaluating quantitative data. Protozoal metabolism is of particular interest here given the paucity of quantitative data.

Empirical models lack the biological basis necessary to evaluate mitigation strategies to reduce excretion of waste, including nitrogen, phosphorus and methane. Such models may have little predictive value when comparing various feeding strategies. Examples include the Intergovernmental Panel on Climate Change (IPCC) Tier II models to quantify methane emissions and current protein evaluation systems to evaluate low protein diets to reduce nitrogen losses to the environment. Nutrient based mechanistic models can address such issues. Since environmental issues generally attract more funding from governmental offices, further development of nutrient based models may well take place within an environmental framework.

Keywords: feed evaluation, models, nutrient profiles, rumen fermentation

\section{Introduction}

Feed evaluation is the use of methods to describe feedstuffs with respect to their ability to sustain different types and levels of animal performance. Nutritionists and farmers

\footnotetext{
${ }^{\dagger} E-m a i l:$ jan.dijkstra@wur.n
}

in the livestock industry apply feed evaluation systems to match dietary nutrients with those required to support a desired level of production. The practical importance of feed evaluation is obvious with respect to optimising efficiency of feed utilisation, production and financial return to the producer. Provision of inadequate nutrients 
relative to the desired production level may compromise production resulting in a negative economic impact on the dairy farm and may have adverse effects on the animal (e.g. ketosis due to glucose shortage). On the other hand, provision of excess nutrients can also have undesirable effects on the animal (e.g. over-conditioning). Moreover, reducing the level of excess nutrients is important in minimising pollution of the environment.

In current feed evaluation systems worldwide, the amounts of energy, protein, vitamins and minerals available for absorption from the gastro-intestinal tract (GIT) are represented, followed by quantitative approaches to describe the required amounts for maintenance and production using a factorial approach. These systems have several drawbacks that are well recognised (e.g. Baldwin, 1995; Dijkstra et al., 2002; Hanigan, 2005). Single energy or protein values for a feed quote static conditions, whereas the energy or protein supply depends on a number of interrelated factors, including site of digestion and level of feed intake. Energy and protein systems have been developed independently, despite vast evidence of the interactions between energy- and protein-yielding nutrients. The level of aggregation hampers inclusion of new concepts and data that arise from experiments conducted at the organ, tissue or cellular levels. Similarly, the current level of aggregation also impedes the integration of concepts that arise from experiments conducted at a higher level of organisation (e.g. climate effects, whole farm aspects, etc.) A major criticism of all energy and protein systems is that they do not predict how performance, in terms of production level and product composition, will change in response to deliberate changes in feeding strategy. Finally, major opportunities to alter milk fat and protein content and composition through nutritional manipulation exist, but its control requires knowledge of delivery of individual nutrients at the mammary gland which is not represented in current systems. To improve upon current prediction schemes, new feeding systems need to be based on mechanisms that govern the response of animals to nutrients, by quantitatively describing metabolite supply at a more detailed level than the current aggregated components.

The problems and challenges in feed evaluation are illustrated by results from an experiment with 16 early lactating dairy cattle (2 to 9 weeks post partum) fed glycogenic or lipogenic diets (Van Knegsel et al., 2006). Diets were devised to provide large amounts of glucogenic nutrients (propionic acid and glucose from escape starch) or large amounts of lipogenic nutrients (acetic and butyric acid and long chain fatty acids), but were equal in net energy (NE), protein digested in the small intestine (DVE) and degraded protein balance (OEB) content, calculated according to the Dutch system (Van Es, 1975; Tamminga et al., 1994). Energy balance was measured by indirect calorimetry. Diet did not affect dry-matter intake (DMI) (20.8 v. $20.7 \mathrm{~kg} /$ day; $P>0.05)$ and thus energy and protein availability did not differ according to the Dutch feeding systems. However, cows on the lipogenic diet partitioned more energy to milk than cows on the glycogenic diet (1175 v. $1073 \mathrm{~kJ} / \mathrm{kg}^{0.75}$ body weight per day; $P<0.05$ ) (Figure $1 \mathrm{a}$ ) and had a higher milk fat yield $(1.89$ v. $1.67 \mathrm{~kg} / \mathrm{day} ; P<0.05)$. Energy mobilised as body fat tended to be higher in cows fed the lipogenic diet than in cows fed the glycogenic diet (190 v. $113 \mathrm{~kJ} / \mathrm{kg}^{0.75}$ body weight per day; $\left.P<0.10\right)$. Energy retention as body fat in cows fed the glycogenic diet was positive from week 8 post partum, whereas cows fed the lipogenic diet still showed negative energy retention (Figure 1b). The results from this study demonstrate that type of energy (lipogenic or glycogenic) in isocaloric, isonitrogenous diets affects the performance of dairy cattle, which was not expected or could not be predicted with current requirement-based feed evaluation systems.

The change from a requirement to a response system to meet the needs of various stakeholders requires prediction of the profile of absorbed nutrients and their subsequent utilisation for various purposes. Variation in responses of animals may be related to differences in the profile of nutrients available for absorption or to differences in
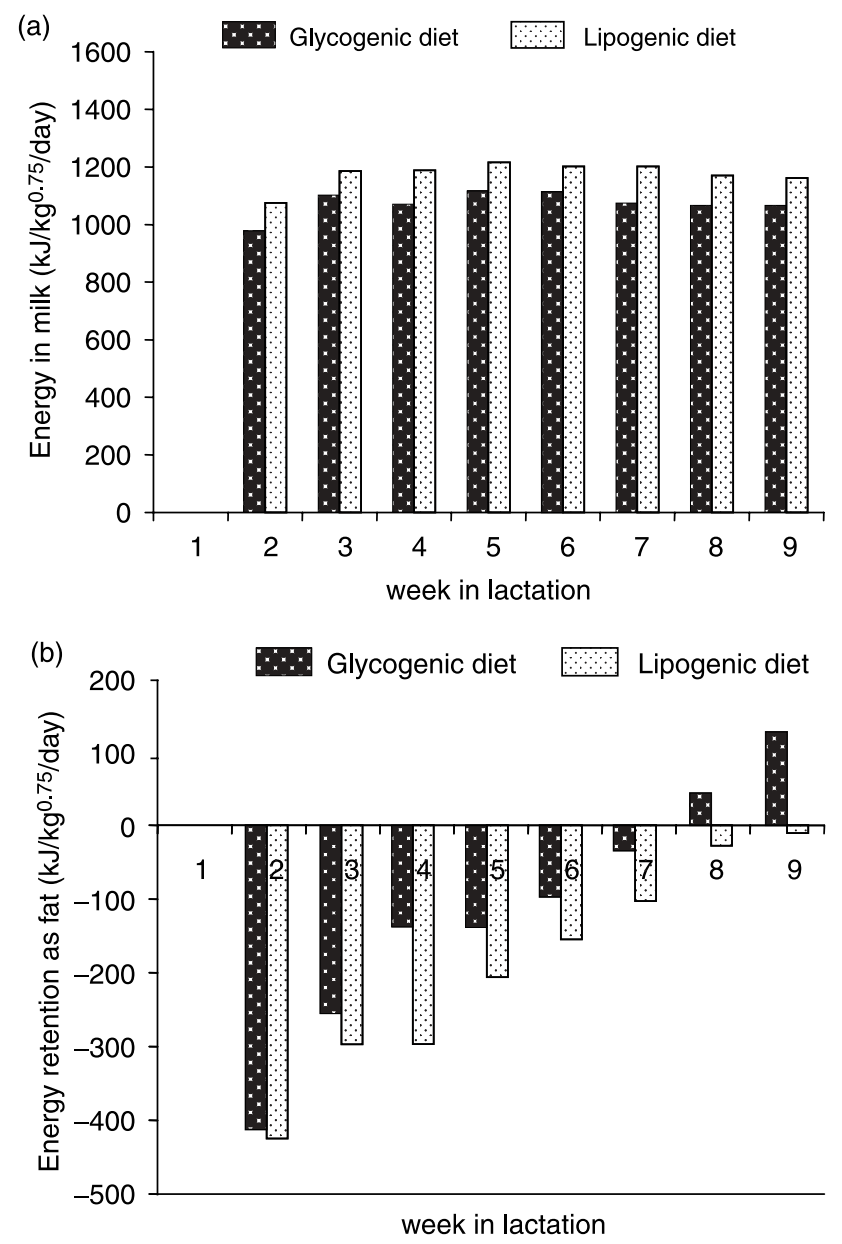

Figure 1 (a) Energy in milk and (b) energy retention as body fat in early lactation dairy cattle fed glycogenic or lipogenic diets (Van Knegsel et al., 2006). Diets were equal in intake and contents of net energy and protein digested in the small intestine. 
partitioning absorbed nutrients for various purposes. The partitioning of absorbed nutrients is described in the contribution of Friggens and Newbold (2007) in this issue. The aims of the present paper are to examine the challenges to predicting the profile of nutrients available for absorption in dairy cattle and to highlight future perspectives for further improved prediction with regard to animal production responses and environmental pollution. Although nutrient based models offer good prospects to prevent nutrient imbalances and reduce the occurrences of related metabolic diseases (including rumen acidosis, ketosis and abomasal displacement; Goff, 2006), health and reproduction issues are outside the scope of the present paper. The paper focuses on fermentation processes in the reticulo-rumen (hereafter rumen) as these have a large impact on the profile of nutrients available for absorption. Actual availability of nutrients for production depends on utilisation of absorbed nutrients by the wall of the GIT and the prediction of this utilisation has been reviewed elsewhere (Bannink et al., 2006a). Prediction requires mathematical models and for model classification, development and evaluation the reader is referred to various textbooks (Baldwin, 1995; Dijkstra et al., 2005a; Thornley and France, 2006).

\section{Rumen degradation and passage}

Digestion of feed in the rumen (disappearance of feed entities in the rumen) is the result of two competing processes: degradation and passage. Degradation occurs primarily through the activity of micro-organisms in the rumen, although in fresh forages, plant-derived proteinases may contribute to the first stages of protein degradation (Attwood, 2005). Smaller-sized substrates are then fermented to yield volatile fatty acids (VFA) as well as other endproducts including carbon dioxide and methane. The passage rate determines the time that feed is retained in various compartments of the GIT for digestive action. These processes have to be integrated and described mathematically to predict digestion of feed and production of VFA and microbial matter in the rumen, and to predict the outflow of undigested feed and microbial matter.

\section{Rumen degradation}

Quantitative description of rumen degradation requires appropriate biological data. Information obtained in vivo is the most reliable and should be the reference to assess other methods and to evaluate predictions. However, in vivo trials cannot be considered routine in most laboratories and cannot be carried out for each feeding situation that occurs in practice. Hence a considerable amount of research on in vitro and in sacco techniques has been carried out. Current protein evaluation systems as well as extant mechanistic models require feed degradation parameters as an input. Degradation parameters are usually obtained using the polyester or nylon bag technique (in sacco technique) or the gas production technique. In the in sacco technique, it is assumed that the washout fraction is rapidly degradable and that a truly undegradable fraction exists that remains after prolonged incubation. Based on gas production profiles, the soluble part of the washout fraction of barley and maize was fermented faster than the insoluble washout fraction (Yang et al., 2005). Although in general little escape of soluble substrate from the rumen occurs, degradation is not necessarily complete (e.g. Volden et al. (2002) on outflow of soluble protein and Nocek and Tamminga (1991) on outflow of soluble starch). In most mechanistic models of rumen fermentation, predicted escape of soluble substrates depends upon the concentration of the microbial biomass present as well as the fractional passage rate. A higher microbial biomass will allow increased uptake and metabolism of soluble material, as evidenced by the effect of inoculum concentration on rate of gas production in batch cultures (Rymer et al., 2005). In comparison to current empirical feed evaluation systems in which substrate degradation follows first-order kinetics, the representation of substrate degradation as a second-order kinetic process (degradation being affected by substrate concentration and microbial activity) allows various substrate interactions to be described quantitatively. For example, the rate of degradation of carbohydrates depends in part on the availability of nitrogen (N) sources (Carro and Miller, 1999) through effects on microbial growth.

Whilst the in sacco technique provides information on degradation rates of various individual organic matter (OM) components, the situation is less clear cut with the gas production technique. For prediction of the profile of absorbed nutrients, information on separate OM components is essential, since in contrast to fibre, any protein, starch and lipid that flow out of the rumen may be digested by host enzymes in the small intestine. Moreover, the type of substrate fermented has a significant impact on the type of VFA formed in the rumen of dairy cattle (Bannink et al., 2006b), necessitating various OM components to be distinguished. However, the gas production technique measures gas that arises from fermentation of all OM components in the substrate incubated, and further techniques are required to obtain data on fermentation of OM components. One approach is to interpret the various phases observed in gas production profiles. The first phase of the gas production profile, in the early stages of incubation, is assumed to be related to an easily fermentable, soluble fraction, whilst the second phase might be related to fermentation of plant cell walls. In contrast, different phases may also occur upon separate incubation of fractionated plant material (Williams et al., 2000) or of pure carbohydrates (Mould et al., 2000), including glucose. In other efforts to distinguish OM into components, a curve subtraction technique has been proposed based on incubation of whole and neutral-detergent fibre (NDF) extracted material (Stefanon et al., 1996). The accuracy of this technique depends, among others, on the assumption 
that extraction does not affect degradation of the fractions. Yet the fibre structure may be partially disrupted by neutral-detergent extraction, giving rise to elevated fibre degradation rates and invalidating the underlying assumption of the curve subtraction technique (Kennedy et al., 1999; Ruiz et al., 2002). For mechanistic models, the use of the gas production technique may provide valuable qualitative information especially when the technique is used to study more fundamental aspects of fermentation. However, given the above considerations and since the gas production technique is a batch culture process, its potential as a source of quantitative data for mechanistic models, based on individual substrates, may be inherently limited (Dijkstra et al., 2005b).

\section{Rumen passage}

In contrast with the extensive amount of data available on substrate degradation rates, availability of data on ruminal retention times is relatively scarce. Compartmental analyses of the in sacco (Lopez et al., 1999) and gas production techniques (France et al., 2005) have been applied to derive the link between these methods and actual in vivo degradation of nutrients in the rumen. These analyses clearly indicated the significant effect of rate of passage upon calculated extent of degradation. Accounting for the retention time in the rumen is a pre-requisite for many feed evaluation systems (Agricultural and Food Research Council (AFRC), 1993; National Research Council (NRC), 2001; Thomas, 2004). Moreover, the fractional rate of passage is also a major determinant of microbial protein efficiency (discussed in the next section). Passage from the rumen is a complex process that involves mixing, disruption and comminution of various components. The rumen operates as a partially stirred, continuous-flow reactor and different sub-compartments with different flow characteristics may be distinguished: liquid, escapable particles, and retained particles. To estimate passage dynamics of feed particles, often external markers (rare earth and chromium markers) or inert internal markers (acid-insoluble ash and indigestible fibre fractions) are used. Results of passage studies using external markers show that fractional passage rates are feed specific and vary with factors including roughage to concentrate ratio, chemical composition and feed intake level (Colucci et al., 1990; Rinne et al., 1997). For external markers of particle passage, it is assumed that they represent the passage behaviour of the particles ingested with the diet. However, applicability of the results have been criticised because external markers may restrict the digestibility of the particles they are linked to, they may bind preferentially to small particles, and they may migrate to rumen fluid (Uden et al., 1980; Siddons et al., 1985; Combs et al., 1992). The inert internal markers referred to earlier, circumvent these problems as they form intrinsic components of the feed particles. However, these markers are not unique and cannot be distinguished from the bulk material. Hence, information on passage dynamics from the rumen demands knowledge of the pool size and this can only be obtained from rumen evacuations or slaughter. These are time consuming and labour intensive procedures and require that the animals are in steady-state or that the rumen is evacuated frequently. Therefore, it is desirable to use markers that evade the aforementioned limitations, and that are representative of the in vivo situation. Stable isotopes $\left({ }^{13} \mathrm{C},{ }^{15} \mathrm{~N}\right)$ appear to be suitable internal markers to meet these conditions (Südekum et al., 1995; Huhtanen and Hristov, 2001). When bound to different feed fractions, isotope markers may also be used to quantify the passage rate of these individual fractions. An example using ${ }^{13} \mathrm{C}$ enriched grass silage (grass was a mixture of ryegrass (Lolium perenne L.) and timothy grass (Phleum pratense L.; Pellikaan, 2004)) is presented in Figure 2. Faecal excretion of ${ }^{13} \mathrm{C}$ labelled feed components was fitted using the multi-compartmental model described by Dhanoa et al. (1985) and goodness-of-fit parameters indicated an accurate fit. As expected, various feed fractions did not behave identical, and fractional passage rate from the rumen of the NDF fraction was lower than that of dry matter (DM). Upon comparison with Cr-mordanted NDF, the internal markers had markedly lower fractional passage rates (Table 1). Such lower fractional passage rates when using internal markers may be related to the fact that in this study, the ${ }^{13} \mathrm{C}$-labeled grass was cut to a size of 3 to $5 \mathrm{~cm}$ before entering the rumen, whilst $\mathrm{Cr}$-mordanted NDF was ground to pass a $0.5-\mathrm{mm}$ sieve. Moreover, mordanting fibre with $\mathrm{Cr}$ restricts the digestibility of the labelled particles, thus affecting passage kinetics. In contrast, the internal marker particles are subject to usual fermentation in the rumen and the lower functional specific weight during active fermentation may have retarded their passage out of the rumen (Kaske et al., 1992). Both internal and external markers indicated a higher fractional passage rate at higher intake levels (Table 1). However, the effect on fractional passage of grass regrowth period ( 6 v. 12 weeks, with

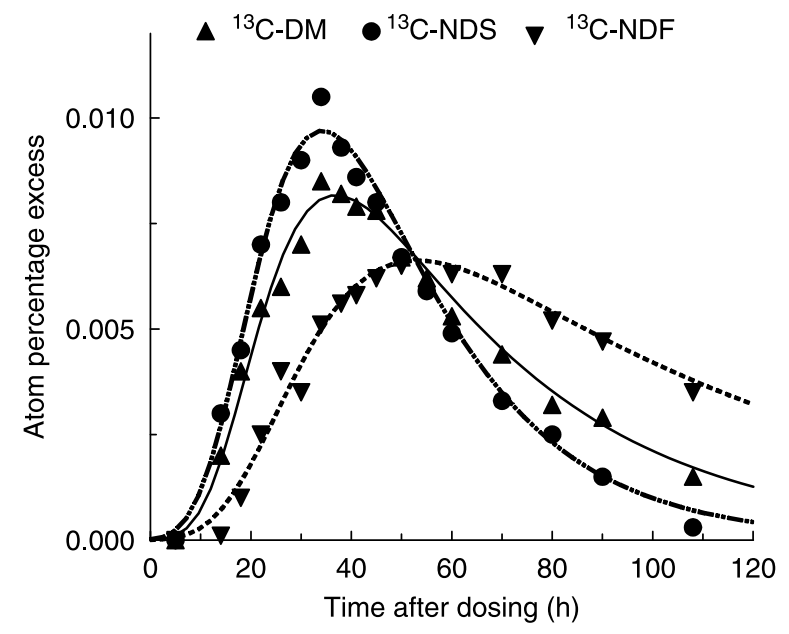

Figure 2 Faecal excretion patterns of ${ }^{13} \mathrm{C}$-enriched grass silage chemical components (DM, dry matter; NDS, neutral-detergent solubles; NDF, neutral-detergent fibre) in dairy cattle (data from Pellikaan, 2004). Grass was a mixture of ryegrass (Lolium perenne L.) and timothy grass (Phleum pratense L.). Line fitted using the multicompartmental model of Dhanoa et al. (1985). 
Table 1 Fractional rumen passage rates (per h) of grass silage in dairy cattle at DM intake levels of 7.0 and $12.3 \mathrm{~kg} /$ day and ensiled after a grass regrowth period of 6 or 12 weeks using various external and internal markers. Grass was a mixture of ryegrass (Lolium perenne L.) and timothy grass (Phleum pratense L.). Data from Pellikaan (2004)

\begin{tabular}{|c|c|c|c|c|c|}
\hline & \multicolumn{2}{|c|}{$\begin{array}{l}\text { External } \\
\text { markers }\end{array}$} & \multicolumn{3}{|c|}{$\begin{array}{l}\text { Internal } \\
\text { markers }^{\dagger}\end{array}$} \\
\hline & Co-EDTA & Cr-NDF & ${ }^{13} \mathrm{C}-\mathrm{DM}$ & ${ }^{13} \mathrm{C}-\mathrm{NDF}$ & ${ }^{13}$ C-NDS \\
\hline \multicolumn{6}{|l|}{ Intake level: } \\
\hline 7.6 kg DM per day & 0.099 & 0.049 & 0.023 & 0.016 & 0.035 \\
\hline $12.3 \mathrm{~kg} \mathrm{DM}$ per day & 0.104 & 0.069 & 0.034 & 0.028 & 0.040 \\
\hline \multicolumn{6}{|l|}{ Regrowth period: } \\
\hline 6 weeks & 0.133 & 0.053 & 0.036 & 0.020 & 0.049 \\
\hline 12 weeks & 0.105 & 0.054 & 0.030 & 0.017 & 0.040 \\
\hline
\end{tabular}

${ }^{+{ }^{13} \mathrm{C} \text {-enriched chemical components: } \mathrm{DM}=\text { dry matter; NDF }=\text { neutral-deter- }}$ gent fibre; NDS = neutral-detergent solubles.

corresponding digestible OM contents of 0.798 and $0.717 \mathrm{~g} /$ g DM and net energy for lactation contents of 6.4 and $5.5 \mathrm{~kJ} / \mathrm{g} \mathrm{DM}$, respectively) differed depending upon the use of diverse markers. The internal markers indicated a $20 \%$ lower fractional passage rate for the 12-weeks regrowth period compared with the 6 weeks regrowth period of grass, but Cr-mordanted NDF did not indicate such a difference. A major step in predicting the profile of nutrients available for absorption is to recognise that, just as for degradation of individual fractions, the retention time of individual fractions within a feed may differ. The amount of data on passage using internal markers is rather limited at present and this hampers the adoption of such results in feed evaluation systems. Given the significant impact of passage on substrate degradation, microbial efficiency and VFA production, this area requires much more research.

Various feed evaluation systems incorporate empirical equations to predict fractional passage rates, usually of liquid, forages and concentrates (e.g., AFRC, 1993; NRC, 2001; Thomas, 2004). A number of different equations have been developed based on various characteristics including DM intake level, proportion of concentrate or forage in the diet, etc. However, all equations developed to date suffer from low overall predictability. Seo et al. (2006) compared equations used in various systems, and the highest $R^{2}$ values obtained were only 0.25 (liquid passage), 0.40 (concentrate passage) and 0.39 (roughage passage). Clearly, increases in passage prediction accuracy are required. From a mechanistic viewpoint, particle size and functional specific gravity are the most important factors that determine the probability of particles passing out of the rumen (Kaske et al., 1992). Various chemical components may not represent these physical attributes, and interactions between chemical components may affect the change in these attributes within the rumen. Thus, mechanistic predictions of passage require a description of physical properties and dynamic changes in these properties in particular, but to date efforts to represent dynamic changes in particle size and functional specific gravity are largely absent.

\section{Efficiency of microbial protein synthesis}

Microbial protein synthesis (MPS) in the rumen usually provides the majority of amino acids (AA) available for absorption. The total amount of microbial protein flowing to the small intestine depends on nutrient availability in the rumen and efficiency of use of these nutrients by ruminal micro-organisms (see reviews by Bach et al. (2005) and Firkins et al. (2006)). Prediction of the extent of degradation was discussed in the previous section. This section will focus on the efficiency of MPS (EMPS).

In protein evaluation systems, EMPS is usually expressed on an $\mathrm{OM}$ basis (usually in $\mathrm{g}$ microbial protein per $\mathrm{kg} \mathrm{OM}$ degraded). Various OM components differ in energy yield, however, and EMPS values were more statistically revealing in a number of experimental studies when expressed on a carbohydrate rather than an $\mathrm{OM}$ basis (review by Firkins et al. (2006)). In general, empirical protein evaluation systems predict MPS using a constant EMPS value. In some systems, EMPS is variable and depends on, e.g., level of feed intake (AFRC, 1993), fractional passage rate (Thomas, 2004) or fractional degradation rate (Russell et al., 1992). Yet there are many mechanistic factors that affect EMPS. Mathematical equations to describe variation in microbial growth and microbial efficiency in open or closed anaerobic systems are well documented in the literature (notably the work of Pirt (1975)) but are applied surprisingly little in empirical protein evaluation systems for ruminants. Basically, substrate consumption by micro-organisms will follow enzyme kinetics represented by rectangular hyperbola, and efficiency depends upon the partitioning of substrate consumed for growth and non-growth purposes. Critical elements in these equations include the maintenance requirement and the amount of substrate required per unit growth once maintenance has been met. Usually, the goal of rumen nutrition is to maximise EMPS to use ruminal degradable $\mathrm{N}$ as efficiently as possible and to decrease $\mathrm{N}$ losses to the environment. It should be noted that substrate utilised by microbes is partitioned between fermentation end-products (mainly VFA) and microbial biomass formation. Thus an increase in EMPS usually coincides with a decrease in VFA produced per gram of carbohydrate degraded, which reduces the supply of non-protein energy to the animal. The concept of microbial efficiency and production of biomass versus production of fermentation end-products is central to many other fermentative systems as well, but the aim in some other systems (e.g. environmental bioremediation systems like water purification) is to waste as much energy and to produce as least biomass as possible and is thus opposite to that in the rumen. Therefore, mathematical equations developed may be applicable to many fermentative situations with widely different ultimate goals. 
Maintenance requirement comprises any energy or substrate necessary to the growth of the micro-organism and used in such a way that this energy or substrate is not available for biosynthesis. Thus this includes true maintenance as well as endogenous metabolism and spilling of energy or substrates. The significance of the maintenance requirement value for efficiency of microbial growth is illustrated in Figure 3. Isaacson et al. (1975) used chemostat cultures to estimate the maintenance requirements of mixed rumen bacteria and the value derived $(0.05 \mathrm{~g}$ glucose/g bacterial DM per h) is applied in most mechanistic models. However, maintenance values can vary widely according to the bacterial species involved (Russell and Baldwin, 1979) and chemical conditions in the rumen (e.g. osmotic value; Shi and Weimer (1992)). Given the impact of maintenance requirement on microbial growth efficiency in the usual (low) range of growth rates of microbes in the rumen (Figure 3; maintenance requirement raised from 0.05 to $0.15 \mathrm{~g}$ carbohydrate/g microbial DM per h), surprisingly few maintenance requirement values have been reported in literature, and clearly more data are required to improve extant mechanistic models.

Energy spilling may form a significant part of the maintenance requirement. Conceptually, energy spilling can be regarded as energy decoupling between anabolic and catabolic functions of the cell through 'futile cycles'.

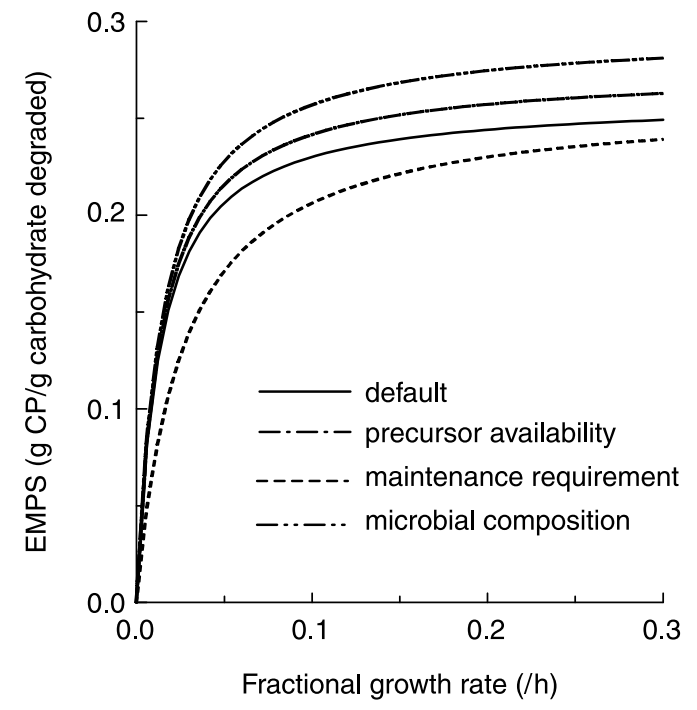

Figure 3 Microbial yield ( $\mathrm{g}$ of microbial crude protein (CP) per $\mathrm{g}$ of carbohydrate) predicted by the double reciprocal equation of Pirt (1975) as affected by maintenance requirement, availability of precursors for microbial growth, and microbial composition. Default situation calculated according to Dijkstra et al. (1992) assuming a maintenance coefficient of $0.05 \mathrm{~g}$ carbohydrate per $\mathrm{g}$ microbial dry matter (DM) per $\mathrm{h}$, a microbial crude protein content of $0.6 \mathrm{~g} / \mathrm{g}$ microbial DM, and ammonia and preformed amino acids to deliver 0.80 and $0.20 \mathrm{~g}$ nitrogen $(\mathrm{N})$ per $\mathrm{g}$ required $\mathrm{N}$. Changes in assumptions: (i) maintenance requirement, maintenance requirement raised to $0.15 \mathrm{~g}$ carbohydrate per $\mathrm{g}$ microbial DM per h; (ii) precursor availability, ammonia and amino acids to deliver 0.40 and $0.60 \mathrm{~g} \mathrm{~N}$ per g required $\mathrm{N}$, respectively; (iii) microbial composition, microbial CP content raised to $0.80 \mathrm{~g} / \mathrm{g}$ microbial DM at the expense of storage polysaccharides in microbial DM.
The term futile cycles describes the concept where the microbial cell has both an irreversible pathway for a chemical transformation process in one direction and a different and irreversible mechanism for the reverse process. If one or the other functions at a different time, metabolism is not wasteful, but if they act simultaneously, there might be no or a small net transformation and the result would be that cellular energy is dissipated, thus reducing EMPS. In the rumen, energy availability is usually the determinant most limiting microbial growth and energy spilling would be of minor importance. However, in certain situations (particularly immediately after feeding a diet high in easily degradable carbohydrates), the availability of nutrients other than energy may limit microbial growth, and spilling of energy in the excess of carbohydrate availability may occur.

In many cases, maintenance activity still remains a relatively fuzzy concept in biological terms but for prediction purposes, representation of the phenomenon seems satisfactory. Pirt (1982) proposed to account mathematically for non-growth requirements by including a constant maintenance energy term independent of the specific growth rate and a term which decreases with increases in specific growth rate. Evaluation of this representation showed good accuracy when compared with observed data, but application to predict EMPS in the rumen would require quantitative data for parameterisation and these are not available. Baldwin (1995) and Dijkstra et al. (1992) used a different representation and adopted a Michaelis-Menten relationship in which the fermentation of carbohydrates to VFA for non-growth purposes was limited by increased availability of $\mathrm{N}$ sources. A similar representation can be applied for other nutrient sources that may impair the biosynthetic use of energy in carbohydrates. The $\mathrm{pH}$ value might also affect the apparent maintenance requirement, as in vitro EMPS decreases at lower $\mathrm{pH}$ values (review by Firkins et al. (2006)). However, Bach et al. (2005) performed a metaanalysis to asses the effect of pH on EMPS, and found no relationship between $\mathrm{pH}$ and EMPS. Ruminal $\mathrm{pH}$ may obviously have a large impact on the degradation of OM (especially fibre). In this respect, to predict MPS in dairy cattle accurately, representation of $\mathrm{pH}$ effects on nutrient degradation is of greater importance than representation of $\mathrm{pH}$ effects on microbial maintenance requirements. Synchronisation of energy from degraded carbohydrate and various $\mathrm{N}$ sources will theoretically increase EMPS by proper matching of nutrients and avoidance of energy spilling, but benefits of synchronisation in vivo are equivocal (Firkins et al., 2006). Recycling of urea- $\mathrm{N}$ to the rumen and temporary storage or depletion of intracellular polysaccharides will assist in overcoming instantaneous deficiencies (Dijkstra et al., 2002). Overall, the practical impact of energy spilling and the need to account for it in models of rumen metabolism seems to be limited in most situations in dairy cattle nutrition. 
In current protein evaluation systems, the source of $\mathrm{N}$ (preformed AA or peptides versus ammonia) usually does not affect MPS or EMPS. However, substrate degradation and bacterial growth have been shown to increase with addition of AA or peptides in fibrolytic and amylolytic bacteria (Bach et al., 2005). In various models, the theoretical improvement in EMPS when all $\mathrm{N}$ required is provided by AA rather than ammonia varied widely: $19 \%$ (Russell et al., 1992), 59\% (Dijkstra et al., 1992) and 77\% (Baldwin, 1995). A major part of the variation in these values can be explained by differences in the units in which EMPS is expressed (i.e. microbial protein per unit OM or per unit carbohydrates degraded). Incorporation of preformed AA or peptides directly into microbial protein, rather than synthesis of AA from ammonia and a carbon skeleton, enables more carbohydrate to be used for other purposes and consequently results in more efficient growth. In Figure 3, the effect of a change in ratio of $\mathrm{N}$ sources used for protein synthesis (default, 0.80 and $0.20 \mathrm{~g} \mathrm{~N}$ per $\mathrm{g} \mathrm{N}$ required delivered by ammonia and $A A$, respectively; alternative, 0.40 and $0.60 \mathrm{~g} \mathrm{~N}$ perg $\mathrm{N}$ required delivered by ammonia and $A A$, respectively) is presented. Current mechanistic models include the effect of $\mathrm{N}$ source by representation of various $\mathrm{N}$-containing substrate pools, and this representation allows for some variation in predicted EMPS.

Crude protein (CP) content of the microbial material flowing to the duodenum varies widely (between 300 and $660 \mathrm{~g} / \mathrm{kg}$ bacterial DM; Clark et al. (1992)). Although some of these differences in composition may be attributed to methodology, major variation in composition related to diet and time after feeding exists when the same techniques are used. Faster fractional microbial growth rates coincide with higher RNA and lower DNA and microbial cell wall contents. In addition high availability of carbohydrates relative to $\mathrm{N}$ sources gives rise to storage of polysaccharides, and $\mathrm{N}$ concentrations in bacteria from cows consuming slowly fermentable carbohydrates are higher than those from cows consuming rapidly fermentable carbohydrates (Bach et al., 2005). The stoichiometry of synthesis of microbial cell components is well established and EMPS calculated theoretically varies significantly with changes in microbial composition (Hespell and Bryant, 1979). Thus, actual expenditure of available $\mathrm{OM}$ or energy by microorganisms to synthesise protein can be very different, depending upon microbial composition. An example is presented in Figure 3. The EMPS increases upon a decrease in storage polysaccharide content (polysaccharide content from 0.2 to $0.0 \mathrm{~g} / \mathrm{g}$ microbial $\mathrm{DM}$ ) and corresponding increase in CP content (from 0.6 to $0.8 \mathrm{~g} / \mathrm{g}$ microbial DM). In contrast, current protein evaluation systems usually assume a fixed total CP content of microbial DM. Moreover, individual AA composition observed in various experiments is not constant and again varies with growth rate and with microbial subpopulation (Martin et al., 1996), whereas current protein evaluation systems assume a constant AA profile of rumen microbial matter. In addition, mechanistic models also do not include a representation of variation in AA composition, likely due to paucity of data. Thus, appreciation of dietary factors affecting abundance of individual groups of micro-organisms and their distinct AA compositions is desired to estimate microbial AA flow accurately. Such variation in composition led Firkins et al. (2006) to conclude that improved procedures and data for measuring and predicting microbial AA flow to the duodenum are required to make real progress in efficient use of protein for production purposes.

Faster fractional microbial growth rates will increase EMPS by reducing the non-growth requirements. Many mathematical functions are available to estimate growth parameters (including fractional growth rate and lag time) in batch (closed) systems (Lopez et al., 2004). In open systems, such as continuous cultures, fractional rate of passage is amongst the most important determinants of fractional microbial growth rate, as in (quasi-) steady state and when no other clearance routes of microbial matter occur, these should be equal (Pirt, 1975). Whilst most empirical protein evaluation systems assume a constant EMPS, some indeed relate EMPS to rate of passage or feed intake level. The Cornell net carbohydrate and protein system and some systems derived from the gas production technique assume fractional microbial growth rate to be related to fractional degradation rate of substrate. However, although such a relationship may be valid for batch cultures, the development of models to describe microbial metabolism shows that this relationship is not directly applicable to repeatedly fed and continuous cultures (reviewed by Dijkstra et al. (2005b)) which are more representative of the in vivo situation. For example, Oba and Allen (2003) found in vivo that EMPS was negatively related to the fractional degradation rate of starch, but positively related to the fractional passage rate of starch.

It is important to note that fractional growth rate of micro-organisms is not exactly equal to fractional passage rate. Another major determinant of net growth, largely ignored in predicting EMPS, is recycling of microbial material within the rumen. The major contribution to microbial turnover is likely to be related to protozoal activities, since protozoa engulf large amounts of bacteria and since a considerable amount of protozoal biomass is recycled within the rumen (Dijkstra et al., 1998). Defaunation of the rumen almost invariably increases EMPS, although MPS is not necessarily increased due to a possible simultaneous reduction in $\mathrm{OM}$ degradation upon defaunation (Jouany et al., 1988). On a variety of diets, simulated recycling of microbial $\mathrm{N}$ in the rumen ranged from 35 to $70 \%$ whilst observed recycling, measured using isotope dilution techniques, ranged from 20 to $90 \%$ (Dijkstra et al., 1998). Recycling of microbial protein wastes energy, although the VFA production may well be increased due to recycling. The released AA may be deaminated and this gives rise to further wastage of $\mathrm{N}$ as urea in urine.

Although recycling has a large impact on EMPS, quantitative data are very limited and mathematical 
representation of recycling has not received much attention. The limited knowledge about rumen protozoal metabolism is mostly because of their dependence on live bacteria, which confounds their in vitro culture (Dehority, 2003). A requirement for live bacteria appears to be manifested in particular in culture periods longer than 2 to 4 days. Moreover, a widely accepted marker to measure the protozoal fraction of microbial protein separate from the bacterial fraction is lacking. New molecular techniques such as real-time polymerase chain reaction (PCR), targeting the gene encoding 185 rDNA to quantify the amount of protozoal biomass (Sylvester et al., 2004), may be promising tools to obtain more quantitative data on protozoa. Protozoal predation is usually represented by rectangular hyperbola, assuming that at low concentrations of microbes, protozoa search thoroughly to secure an adequate uptake of microbial matter, whereas at high microbial concentrations, protozoa reduce their search efforts because of satiation. On a wide range of predator species, the rectangular hyperbola has been found to provide a good description of experimental data (Brown and Rothery, 1993), and this relationship was also central to the levels of predicted recycling mentioned previously (Dijkstra et al., 1998). Information on preferential uptake of certain bacterial species does not reveal a consistent pattern (review by Coleman (1989)). The engulfment of solid feed particles by protozoa is well known and this is also expected to result in engulfment of bacteria attached to these particles. On the other hand, the converse hypothesis of protection against engulfment by means of attachment, has been supported by observations that the fluid-phase, non-fibrolytic bacteria increase to a far higher extent upon defaunation than do the attached bacteria (Weimer, 1992). However, it should be noted that the preference of protozoa for starch and sugars, rather than fibre, will result in a relatively higher availability of starch and sugars compared to fibre upon defaunation and hence a smaller increase in attached, fibrolytic bacteria compared to non-attached bacteria. Interestingly, Rasmussen et al. (2005) reported that some bacterial pathogens appear to be resistant to degradation in vacuoles of mixed rumen protozoa. Survival of several types of Salmonella in vacuoles, in particular multiresistant types, results in higher intestinal cell invasion capacity. On the other hand, toxin-producing Escherichia coli were not engulfed by or attached to mixed ciliate protozoa (Burow et al., 2005). Representation of uptake and digestion of bacteria by protozoa is further complicated because of adaptive mechanisms that bacteria develop to survive protozoal predation. Adaptive mechanisms to increase the survival of bacteria under predation pressure include changing cell surface properties, modification of swimming speed, secretion of bioactive metabolites, or formation of micro-colonies (Matz and Kjelleberg, 2005). Given the large impact of microbial turnover on microbial efficiency and the small amount of experimental data, it appears that mathematical representation of selective engulfment and digestion of bacteria by protozoa may well be improved further. Quantification of microbial recycling will help to establish more accurate estimates of microbial protein yield factors to be applied in protein evaluation systems.

Finally, it is essential to note that virtually all of our present quantitative knowledge on microbial metabolism in the rumen and consequently its mathematical representation is based on culturable rumen microbial species. Recent molecular techniques indicate that understanding on the presence of various microbial species is far from complete though. For example, Edwards et al. (2004) showed that only $11 \%$ of the diversity of the rumen microbial ecosystem is represented by cultured isolates. Hence the information on biochemical properties used to develop mechanistic models may represent only a small fraction of the properties of the total microbial population in the rumen. Molecular techniques may give a wealth of information, but to include such findings in systems predicting the nutrient profile requires quantitative rather than qualitative data as well as close collaboration between molecular scientists and mathematical modellers on interpreting and evaluating data. Novel cultivation techniques have been described that have shown success in the isolation and cultivation of previously unculturable organisms (Kaeberlein et al., 2002) but none of these systems is suitable for application to anaerobic ecosystems. Application of such novel cultivation approaches to the rumen ecosystem will contribute directly to increasing the understanding of microbial metabolic and fermentation processes by recovering in culture previously uncultivable organisms, and may lead to further improvements in the mechanistic representation of MPS.

\section{Environmental pollution}

Usually, feed accounts for the major part of all costs on a dairy farm. Numerous studies have demonstrated that nutrition has a major impact on milk production and thus on farm profitability. Milk production responses to increased nutrient intake usually show a curvilinear pattern that follows the law of diminishing returns. Dietary intake or nutrient density at which efficiency of production (output divided by input) is maximised is by and large different from that which maximises financial profits (VandeHaar and St-Pierre, 2006). As a consequence, surpluses of nutrients that may negatively affect the environment have increased dramatically with increased production levels. Nutrients causing environmental concern are in particular those containing excessive nitrogen $(\mathrm{N})$, phosphorus $(\mathrm{P})$ and potassium (K) (Tamminga, 2003). Nitrogen surpluses are associated with losses from the farm system through ammonia volatilisation, nitrate leaching, and dissipation as $\mathrm{N}_{2}, \mathrm{~N}_{2} \mathrm{O}, \mathrm{NO}$ and $\mathrm{NO}_{2}$ which negatively affect the quality of surface and groundwater and air. $\mathrm{P}$ wastes from dairy farms are associated with eutrophication in streams and lakes. Another major environmental concern is global 
warming. Enteric fermentation in cattle gives rise to methane excretion which is a potent greenhouse gas. Thus nutrition has a large impact on profitability as well as on environmental sustainability, and a proper balance is sought by farmers and governments.

Given the environmental concerns, there is increasing interest in investigating the potential of specific on-farm measures and of government policies to reduce wastes (Tamminga, 2003; Rotz, 2004). The formulation of strategies requires first of all accurate estimates of excretion of waste, with monitoring surveys indicating the actual state of emissions. Secondly, analyses of management strategies to mitigate emissions under specific farming circumstances are needed. Such strategies require not just data and knowledge on an animal level, but also on other subsystems of the farm, including crops and soil, and therefore whole-farm models are developed.

A common characteristic of these whole farming approaches is that static, empirical representations are used for the individual subsystems with presumed values for transfer rates between these subsystems, such as the efficiency of feed conversion into milk and manure, emission rates and fertilising value of manure, and losses from soil. Such models are relevant for recognition of the relationship between whole farm performance and management within the individual subsystems. However, they have limited applicability to individual farms. Index values are derived from registered farm performance or from general values in databases. These models cannot relate to the level of detail involved with farmer experience and the precise conditions met at a specific farm, nor can they be applied to enhance innovation within subsystems (Sterk et al., 2006). Proper integration of the subsystems into a whole farm model requires appreciation of variation within a subsystem and the interactions between subsystems. For example, reductions in the amount of fertiliser- $\mathrm{N}$ may increase $\mathrm{N}$ efficiency on the soil-crop subsystem, but at the same time it may result in grass characterised by a lower protein content and degradability and in lower feed intake and milk production at the animal sublevel (Valk et al., 2000). Rotz et al. (2005) developed such an integrated beef herd model with the animal subsystem based on nutritional requirements using the Cornell net carbohydrate and protein system. In this model, the response of animals to changes in the diet was achieved through iterative solutions using linear programming techniques. The recognition of variation within the animal subsystem is an important element in this model. However, the drawbacks of current empirical energy and protein systems described in the previous sections also limit prediction of animal response and subsequently excretion of unused nutrients. Another example is the whole-farm model with five subsystems (animal, feed, manure, soil, crop) of Schils et al. (2005) to estimate methane emissions. In the animal submodel, methane production is a linear function of milk production assuming a fixed conversion factor of $0.01 \mathrm{~kg}$ methane produced per cow per year per kg milk. Equally, the Intergovernmental Panel on Climate Change (IPCC) recommends calculation of methane emissions based on a fixed conversion value of gross energy (GE) to methane (for dairy cattle: $6 \%$ of GE intake, except for diets with a large quantity of grain; IPCC (1997)). However, diet intake and diet composition changes that may result from management changes within the non-animal subsystems, actually cause large variations in the amount of methane per $\mathrm{kg}$ energy intake or milk produced (review by Kebreab et al. (2006)). Thus, empirical models, including current feed evaluation systems, largely lack the biological basis necessary to evaluate mitigation strategies to reduce excretion of waste. Mechanistic models are important tools for assessing mitigating options and for directing experimental research towards options most likely to result in significant reduction of emissions. It is also important that mitigation options take other policies into account. For example, mitigation strategies to reduce methane may impact on nitrate leaching in the soil and ammonia volatilisation into the air. A first attempt to integrate emissions of various key environmental pollutants ( $N, P$ and methane) from dairy cattle within a mechanistic, nutrient-based feed evaluation system was presented by Kebreab et al. (2004).

At present, prediction of surpluses excreted into the environment is based on models originally developed to predict nutrient utilisation by the animal. The increased importance of environmental issues in dairy cattle production will likely open up new opportunities to develop and improve nutritional models, be it from a different perspective. For example, current mechanistic models to estimate methane emission in cattle are based on nutritional models developed to predict the type of nutrient available for absorption (Mills et al., 2001). In these mechanistic models, the stoichiometry of VFA formation is essential as the type of VFA absorbed is usually categorised into glucogenic or lipogenic, and the ratio between glucogenic or lipogenic nutrients affects milk production and composition as well as energy balance of dairy cattle (Van Knegsel et al., 2005). At the same time the production of methane is also related to the type of VFA formed. Consequently, models of rumen fermentation developed to predict the profile of nutrients available for absorption were subsequently applied to predict methane production. Further improvements in VFA stoichiometry were partly driven by interest in methane mitigation options. Bannink et al. (2005) included the effect of ruminal pH on VFA stoichiometric parameters related to type of substrate fermented, which indicated the profound effect of type of substrate fermented as well as of rumen $\mathrm{pH}$ on predicted methane yield (Table 2). Some mitigation strategies to reduce methane emissions, including the addition of fats (in particular unsaturated fatty acids and lauric and myristic acids; Giger-Reverdin et al. (2003)) and of organic acids (including fumarate and malate; Castillo et al. (2004)), are not yet covered by mechanistic models, although they affect the profile of nutrients available for absorption. Similarly, reduction in methane emissions from the rumen may be 
Table 2 Methane production from various substrates based on volatile fatty acid stoichiometry derived without variation in rumen $\mathrm{pH}$ ( $\mathrm{pH}$ not considered as independent variable) and with rumen $\mathrm{pH}$ variation ( $\mathrm{pH}$ included as independent variable) in diets composed mainly of roughages $(R)$ or concentrates $(C)$ (adapted from Bannink et al. (2005). When $\mathrm{pH}$ was included, values are given for $\mathrm{pH} 5.5$ and $\mathrm{pH} 6.5$

\begin{tabular}{|c|c|c|c|c|c|c|}
\hline \multirow[b]{4}{*}{ Substrate } & \multicolumn{6}{|c|}{ Methane yield ( $\mathrm{kJ} / \mathrm{g}$ substrate fermented) } \\
\hline & \multicolumn{2}{|c|}{$\begin{array}{l}\text { Without rumen } \\
\text { pH variation }\end{array}$} & \multicolumn{4}{|c|}{$\begin{array}{l}\text { With rumen } \\
\mathrm{pH} \text { variation }\end{array}$} \\
\hline & \multirow[b]{2}{*}{$\mathrm{R}$} & \multirow[b]{2}{*}{ C } & \multicolumn{2}{|c|}{ Rumen $\mathrm{pH} 5.5$} & \multicolumn{2}{|c|}{ Rumen $\mathrm{pH} 6.5$} \\
\hline & & & $\mathrm{R}$ & C & $\mathrm{R}$ & C \\
\hline Starch & 2.40 & 2.02 & 1.95 & 1.69 & 2.49 & 2.11 \\
\hline Soluble sugars & 3.68 & 2.92 & 2.68 & 1.95 & 3.98 & 3.18 \\
\hline Hemi-cellulose & 2.53 & 3.07 & 2.36 & 3.38 & 2.36 & 3.38 \\
\hline Cellulose & 2.70 & 3.74 & 2.30 & 3.10 & 2.30 & 3.10 \\
\hline
\end{tabular}

partly offset by increased emissions from hindgut fermentation or subsequently in slurry methanogenesis (Hindrichsen et al., 2006), which for predictions on the animal sublevel require models of hindgut fermentation. Research into such strategies may attract more funding from governmental offices than research with production oriented goals. Thus further development of nutrient based models may well take place within an environmental framework.

Current empirical and mechanistic models to predict the profile of nutrients available for absorption at the animal sublevel generally do not contain sufficient detail to provide input for the crop and soil sublevels. The environmental impact of $\mathrm{N}$ excreted in faeces and urine depends on a number of factors, including the manure $\mathrm{N}$ and OM composition, in turn largely affected by diet composition and intake level. Increasing the level of dietary $\mathrm{CP}$ not only increases total excretion of $\mathrm{N}$ in faeces and urine, but generally gives a proportionally larger rise in urinary $\mathrm{N}$ excretion (Castillo et al., 2000), which has been associated with increased ammonia volatilisation. Other manure characteristics, including $\mathrm{pH}$, may affect ammonia volatilisation though (Misselbrook et al., 2005). Mineralisation of organic $\mathrm{N}$ in slurry is negatively related to fibre content of the slurry, and the uptake of $\mathrm{N}$ from slurry by plants and losses from the soil also depends on the form of faecal $\mathrm{N}$ and the ratio between $\mathrm{C}$ and $\mathrm{N}$ in the faeces (Powell et al., 2006). Urea in faeces is rapidly converted into ammonia and potentially immediately available for plant uptake. Undigested feed $\mathrm{N}$ in faeces is relatively recalcitrant in soils and mineralises slowly, and is therefore unavailable to plants over the short term. Availability to plants of faecal organic $\mathrm{N}$ arising from endogenous secretions in the GIT and from undigested microbial protein is intermediate to that of ammonium- $\mathrm{N}$ and undigested feed $\mathrm{N}$. Hence the prediction of $\mathrm{N}$ excretion in faeces and urine of dairy cattle and its subsequent fate in plants, soil, water or air depends on the composition of faeces and urine, and requires mathematical description of the fermentation and digestion processes in the gut. An example of further development of a nutritional model to predict faecal and urinary composition was presented recently by Reijs et al. (2006). They expanded the mechanistic rumen model of Dijkstra et al. (1992) with static equations to describe digestion processes in the intestines and to describe excretion of various urinary components. The model predicts $\mathrm{OM}, \mathrm{C}$ and $\mathrm{N}$ excretion of various faecal and urinary components. Based on the $\mathrm{C}: \mathrm{N}$ ratio of faecal and urinary components, $\mathrm{N}$ excretion was partitioned into three fractions according to potential availability to crops, viz. an immediately available fraction $\left(N_{M}\right)$, easily decomposable fraction $\left(N_{E}\right)$ and a resistant fraction $\left(\mathrm{N}_{\mathrm{R}}\right)$. Simulations were performed for four different ryegrass silage types with a high or low fertilisation rate (350 and $175 \mathrm{~kg} \mathrm{~N}$ per ha per year) and an early or late cutting regime (3000 or $4500 \mathrm{~kg}$ DM per ha). Some results are presented in Figure 4 . The results indicate a wide variation in total $\mathrm{N}$ excretion, $\mathrm{C}: \mathrm{N}$ ratio of faecal $\mathrm{DM}$, and in contribution of $\mathrm{N}_{\mathrm{M}}, \mathrm{N}_{\mathrm{E}}$ and $\mathrm{N}_{\mathrm{R}}$ to total $\mathrm{N}$ excretion. Thus management strategies to adjust silage characteristics have a large impact on simulated total $\mathrm{N}$ excretion and excreta composition that may affect plant and soil use of $\mathrm{N}$ and impact on the environment. Animal manure should be treated as a commodity rather than a waste in wholefarm systems (Tamminga, 2003). Such modelling efforts also indicate that further improvements in representation of post-ruminal processes are required to predict manure composition. As before, these improvements may help improve the prediction of nutrient availability to the animal as well, although from a different angle. It is important to note that variation at the plant level has a significant bearing upon response at the animal sublevel, and in whole farm evaluation of mitigation strategies this interaction should not be ignored (Rotz, 2004).

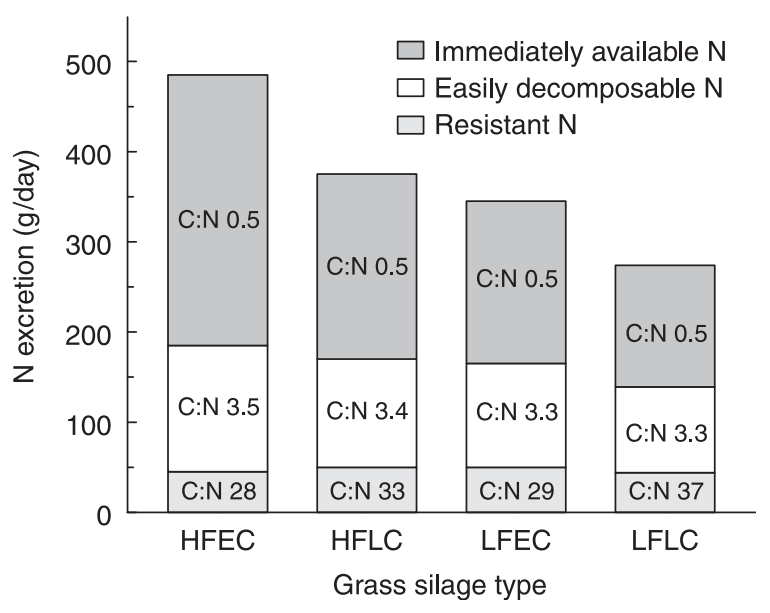

Figure 4 Simulated faecal and urinary $\mathrm{N}$ excretion as various $\mathrm{N}$ fractions and corresponding $\mathrm{C}: \mathrm{N}$ ratio for different diets based on four grass silage types (HFEC $=$ high fertilisation and early cut, HFLC $=$ high fertilisation and late cut, LFEC = low fertilisation and early cut, LFLC = low fertilisation and late cut). Total C:N ratio was 4.1 (HFEC), 5.9 (HFLC), 5.7 (LFEC) and 8.0 (LFLC). Adapted from Reijs et al. (2006). 


\section{Conclusions}

In dairy cattle, a change from a requirement to a response system to meet the needs of various stakeholders necessitates prediction of the profile of absorbed nutrients and its subsequent utilisation for various purposes. Integration of new experimental research findings requires mechanistic models that can incorporate new concepts and data. This contribution highlighted a number of key issues in further development of models that predict the profile of nutrients available for absorption, including fractional passage rates out of the rumen and variation in rumen microbial efficiency. Increasing interest in environmental issues will stimulate further development of nutrient based mechanistic models within an environmental framework. Strategies to mitigate waste emissions at the whole-farm level need to include variation at the animal sublevel.

\section{References}

Agricultural and Food Research Council 1993. Energy and protein requirements of ruminants. CAB International, Wallingford, UK.

Attwood GT 2005. The contribution of plant-derived proteinases to the breakdown of fresh pasture protein in the rumen. British Journal of Nutrition 93, 421-423.

Bach AS, Calsamiglia S and Stern MD 2005. Nitrogen metabolism in the rumen. Journal of Dairy Science 88, (suppl. E) E9-E21.

Baldwin RL 1995. Modeling ruminant digestion and metabolism. Chapman and Hall, London.

Bannink A, Dijkstra J, Koopmans S-J and Mroz Z 2006a. Physiology, regulation and multifunctional activity of the gut wall: a rationale for multicompartmental modelling. Nutrition Research Reviews 19, 227-253.

Bannink A, Dijkstra J, Mills JAN, Kebreab E and France J 2005. Nutritional strategies to reduce enteric methane formation in dairy cows. In Emissions from European agriculture (eds T Kuczynski, U Dämmgen, J Webb and A Myczko), pp. 367-376. Wageningen Academic Publishers, Wageningen, The Netherlands.

Bannink A, Kogut J, Dijkstra J, France J, Kebreab E, Van Vuuren AM and Tamminga S 2006b. Estimation of the stoichiometry of volatile fatty acid production in the rumen of lactating cows. Journal of Theoretical Biology 238, 36-51.

Brown D and Rothery P 1993. Models in biology: mathematics, statistics and computing. John Wiley and Sons Ltd., Chichester.

Burow LC, Gobius KC, Vanselow BA and Klieve AV 2005. A lack of predatory interaction between rumen ciliate protozoa and Shiga-toxin producing Escherichia coli. Letters in Applied Microbiology 40, 117-122.

Carro DM and Miller EL 1999. Effect of supplementing a fibre basal diet with different nitrogen forms on ruminal fermentation and microbial growth in an in vitro semi-continuous culture system (RUSITEC). British Journal of Nutrition 82, 149-157.

Castillo AR, Kebreab E, Beever DE and France J 2000. A review of efficiency of nitrogen utilisation in dairy cows and its relationship with the environmental pollution. Journal of Animal and Feed Sciences 9, 1-32.

Castillo C, Benedito JL, Mendez J, Pereira V, Lopez- Alonso M, Miranda M and Hernandez J 2004. Organic acids as a substitute for monensin in diets for beef cattle. Animal Feed Science and Technology 115, 101-116.

Clark JH, Klusmeyer TH and Cameron MR 1992. Microbial protein synthesis and flows of nitrogen fractions to the duodenum of dairy cows. Journal of Dairy Science 75, 2304-2323.

Coleman GS 1989. Protozoal-bacterial interactions in the rumen. In The roles of protozoa and fungi in ruminant digestion (eds JV Nolan, RA Leng and DI Demeyer), pp. 13-27. Penambul Books, Armidale, Australia.

Colucci PE, MacLeod GK, Grovum WL, McMillan I and Barney DJ 1990. Digesta kinetics in sheep and cattle fed diets with different forage to concentrate ratios at high and low intakes. Journal of Dairy Science 73, 2143-2156.
Combs DK, Shaver RD and Satter LD 1992. Retention of rare earths by hay particles following incubation in fresh or autoclaved rumen fluid. Journal of Dairy Science 75, 132-139.

Dehority BA 2003. Rumen microbiology. Nottingham University Press, Nottingham.

Dhanoa MS, Siddons RC, France J and Gale DL 1985. A multicompartmental model to describe marker excretion patterns in ruminant faeces. British Journal of Nutrition 53, 663-671.

Dijkstra J, Forbes JM and France J 2005a. Quantitative aspects of ruminant digestion and metabolism, Second edition. CAB International, Wallingford, UK.

Dijkstra J, France J and Tamminga S 1998. Quantification of the recycling of microbial nitrogen in the rumen using a mechanistic model of rumen fermentation processes. Journal of Agricultural Science, Cambridge 130, 81-94.

Dijkstra J, Kebreab E, Bannink A, France J and Lopez S 2005b. Application of the gas production technique in feed evaluation systems for ruminants. Animal Feed Science and Technology 123-124, 561-578.

Dijkstra J, Mills JAN and France J 2002. The role of dynamic modelling in understanding the microbial contribution to rumen function. Nutrition Research Reviews 15, 67-90.

Dijkstra J, Neal HD St C, Beever DE and France J 1992. Simulation of nutrient digestion, absorption and outflow in the rumen: model description. Journal of Nutrition 122, 2239-2256.

Edwards JE, McEwan NR, Travis AJ and Wallace RJ 2004. 16S rDNA librarybased analysis of ruminal bacterial diversity. Antonie van Leeuwenhoek 86, 263-281.

Firkins JL, Hristov AN, Hall MB, Varga GA and St-Pierre NR 2006. Integration of ruminal metabolism in dairy cattle. Journal of Dairy Science 89, (suppl. E) E31-E51.

France J, Lopez S, Kebreab E, Bannink A, Dhanoa MS and Dijkstra J 2005. A general compartmental model for interpreting gas production profiles. Animal Feed Science and Technology 123-124, 473-485.

Friggens NC and Newbold JR 2007. Towards a biological basis for predicting nutrient partitioning: the dairy cow as an example. Animal 1, 87-97.

Giger-Reverdin S, Morand-Fehr P and Tran G 2003. Literature survey of the influence of dietary fat composition on methane production in dairy cattle. Livestock Production Science 82, 73-79.

Goff JP 2006. Major advances in our understanding of nutritional influences on bovine health. Journal of Dairy Science 89, 1292-1301.

Hanigan MD 2005. Quantitative aspects of ruminant splanchnic metabolism as related to predicting animal performance. Animal Science 80, 23-32.

Hespell RB and Bryant MP 1979. Efficiency of rumen microbial growth: influence of some theoretical and experimental factors on $Y_{\text {ATP. }}$. Journal of Animal Science 49, 1640-1659.

Hindrichsen IK, Wettstein H-R, Machmüller A and Kreuzer M 2006. Methane emission, nutrient degradation and nitrogen turnover in dairy cows and their slurry at different milk production scenarios with and without concentrate supplementation. Agriculture, Ecosystems and Environment 113, 150-161.

Huhtanen P and Hristov AN 2001. Estimating passage kinetics using fibrebound $15 \mathrm{~N}$ as an internal marker. Animal Feed Science and Technology 94 , 29-41.

Intergovernmental Panel on Climate Change 1997. Revised 1996 IPCC guidelines for national greenhouse gas inventories: reference manual. UK Meteorological Office, Bracknell, UK.

Isaacson HR, Hinds FC, Bryant MP and Owens FN 1975. Efficiency of energy utilization by mixed rumen bacteria in continuous culture. Journal of Dairy Science 58, 1645-1659.

Jouany JP, Demeyer DI and Grain J 1988. Effect of defaunating the rumen. Animal Feed Science and Technology 21, 229-265.

Kaeberlein T, Lewis K and Epstein SS 2002. Isolating "uncultivable" microorganisms in pure culture in a simulated natural environment. Science 296, 1127-1129

Kaske M, Hatiboglu S and Engelhardt WV 1992. The influence of density and size of particles on rumination and passage from the reticulo-rumen of sheep. British Journal of Nutrition 67, 235-244.

Kebreab E, Clark K, Wagner-Riddle C and France J 2006. Methane and nitrous oxide emissions from Canadian animal agriculture: a review. Canadian Journal of Animal Science 86, 135-158. 
Kebreab E, Mills JAN, Crompton LA, Bannink A, Dijkstra J, Gerrits WJJ and France J 2004. An integrated mathematical model to evaluate nutrient partition in dairy cattle between the animal and its environment. Animal Feed Science and Technology 112, 131-154.

Kennedy PM, Lowry JB and Conlan LL 1999. Isolation of grass cell walls as neutral detergent fibre increases their fermentability for rumen micro-organisms. Journal of Science of Food and Agriculture 79, 544-548.

Lopez S, France J, Dhanoa MS, Mould F and Dijkstra J 1999. Comparison of mathematical models to describe disappearance curves obtained using the polyester bag technique for incubating feeds in the rumen. Journal of Animal Science 77, 1875-1888.

Lopez S, Prieto M, Dijkstra J, Dhanoa MS and France J 2004. Statistical evaluation of mathematical models for microbial growth. International Journal of Food Microbiology 96, 289-300.

Matz C and Kjelleberg S 2005. Off the hook - how bacteria survive protozoan grazing. Trends in Microbiology 13, 302-307.

Martin C, Bernard L and Michalet-Doreau B 1996. Influence of sampling time and diet on amino acid composition of protozoal and bacterial fractions from bovine ruminal contents. Journal of Animal Science 74, 1157-1163.

Mills JAN, Dijkstra J, Bannink A, Cammell SB, Kebreab E and France J 2001. A mechanistic model of whole-tract digestion and methanogenesis in the lactating dairy cow: model development, evaluation and application. Journal of Animal Science 79, 1584-1597.

Misselbrook TH, Powell JM, Broderick GA and Grabber JH 2005. Dietary manipulation in dairy cattle: Laboratory experiments to assess the influence on ammonia emissions. Journal of Dairy Science 88, 1765-1777.

Mould FL, Mauricio RM and Owen E 2000. Cumulative and rate of gas release profiles of pure carbohydrates fermented in vitro using the Reading pressure technique. In Gas production: fermentation kinetics for feed evaluation and to assess microbial activity (eds ER Deaville, BA Williams and J Cone), pp. 27-28. British Society of Animal Science, Edinburgh.

National Research Council 2001. Nutrient requirements of dairy cattle, Seventh revised edition. National Academy Press, Washington DC.

Nocek JE and Tamminga S 1991. The prediction of nutrient supply to dairy cows from rate and extent of ruminal degradation of ration components. Journal of Dairy Science 74, 3598-3629.

Oba M and Allen MS 2003. Effects of diet fermentability on efficiency of microbial nitrogen production in lactating dairy cows. Journal of Dairy Science 86, 195-207.

Pellikaan WF 2004. Passage of ${ }^{13} \mathrm{C}$-labelled feed components through the digestive tract of dairy cows. Ph.D. thesis, Wageningen University, Wageningen, The Netherlands.

Pirt SJ 1982. Maintenance energy: a general model for energy-limited and energy-sufficient growth. Archives Microbiology 133, 300-302.

Pirt SJ 1975. Principles of microbe and cell cultivation. Blackwell Scientific Publication, Oxford.

Powell JM, Wattiaux MA, Broderick GA, Moreira VR and Casler MD 2006. Dairy diet impacts on fecal chemical properties and nitrogen cycling in soils. Soil Science Society of America Journal 70, 786-794.

Rasmussen MA, Carlson SA, Franklin SK, McCuddin ZP, Wu MT and Sharma VK 2005. Exposure to rumen protozoa leads to enhancement of pathogenicity of and invasion by multiple-antibiotic-resistant Salmonella enterica bearing SGI1. Infection and Immunity 73, 4668-4675.

Reijs JW, Bannink A, Bosma P and Dijkstra J 2006. Modelling the impact of dietary adjustments on slurry composition of stall-fed dairy cows. In $\mathrm{N}$ management in agrosystems in relation to the water framework directive. Proceedings of the 14th N Workshop (eds JJ Schroder and JJ Neeteseon), pp. 163-166. Plant Research International, Wageningen, The Netherlands.

Rinne M, Huhtanen P and Jaakkola S 1997. Grass maturity effects on cattle fed silage-based diets. 2. Cell wall digestibility, digestion and passage kinetics. Animal Feed Science and Technology 67, 19-35.

Rotz CA 2004. Management to reduce nitrogen losses in animal production. Journal of Animal Science 82, E119-E137.

Rotz CA, Buckmaster DR and Comerford JW 2005. A beef herd model for simulating feed intake, animal performance, and manure excretion in farm systems. Journal of Animal Science 83, 231-242.

Ruiz R, Tedeschi LO, Marini JC, Fox DG, Pell AN, Jarvis G and Russell JB 2002. The effect of ruminal nitrogen $(\mathrm{N})$ deficiency in dairy cows: evaluation of the
Cornell net carbohydrate and protein system ruminal $\mathrm{N}$ deficiency adjustment. Journal of Dairy Science 85, 2986-2999.

Russell JB and Baldwin RL 1979. Comparison of substrate affinities among several rumen bacteria: a possible determinant of rumen bacterial competition. Applied and Environmental Microbiology 37, 531-536.

Russell JB, O'Connor JD, Fox DG, Van Soest PJ and Sniffen CJ 1992. A net carbohydrate and protein system for evaluating cattle diets. I. Ruminal fermentation. Journal of Animal Science 70, 3551-3561.

Rymer C, Huntington JA, Williams BA and Givens DI 2005. In vitro cumulative gas production techniques: history, methodological considerations and challenges. Animal Feed Science and Technology 123-124, 9-30.

Schils RLM, Verhagen A, Aarts HFM and Sebek LBL 2005. A farm level approach to define successful mitigation strategies for GHG emissions from ruminant livestock systems. Nutrient Cycling in Agrosystems 71, 163-175.

Seo S, Tedeschi LO, Lanzas C, Schwab CG and Fox DG 2006. Development and evaluation of empirical equations to predict feed passage rate in cattle. Animal Feed Science and Technology 128, 67-83.

Shi $Y$ and Weimer PJ 1992. Response surface analysis of the effects of $\mathrm{pH}$ and dilution rate on Ruminococcus flavefaciens FD-1 in cellulose-fed continuous culture. Applied and Environmental Microbiology 58, 2583-2591.

Siddons RC, Paradine J, Beever DE and Cornell PR 1985. Ytterbium acetate as particulate-phase digesta-flow marker. British Journal of Nutrition 54, 509-519.

Stefanon B, Pell AN and Schofield P 1996. Effect of maturity on digestion kinetics of water-soluble and water-insoluble fractions of alfalfa and brome hay. Journal of Animal Science 74, 1104-1115.

Sterk B, Van Ittersum MK, Leeuwis C, Rossing WAH, Van Keulen H and Van de Ven GWJ 2006. Finding niches for whole-farm design models - contradictio in terminis? Agricultural Systems 87, 211-228.

Südekum KH, Ziggers W, Roos N, Sick H, Tamminga S and Stangassinger M 1995. Estimating the passage of digesta in steers and wethers using the ratio of ${ }^{13} \mathrm{C}$ to ${ }^{12} \mathrm{C}$ and titanium (IV) oxide. Isotopes in Environmental and Health Studies 31, 219-227.

Sylvester JT, Karnati SKR, Yu Z, Morrison M and Firkins JL 2004. Development of an assay to quantify rumen ciliate protozoal biomass in cows using realtime PCR. Journal of Nutrition 134, 3378-3384.

Tamminga S 2003. Pollution due to nutrient losses and its control in European animal production. Livestock Production Science 84, 101-111.

Tamminga S, Van Straalen WM, Subnel APJ, Meijer RGM, Steg A, Wever CJG and Blok MC 1994. The Dutch protein evaluation system: the DVE/OEB-system. Livestock Production Science 40, 139-155.

Thomas C 2004. Feed into milk: a new applied feeding system for dairy cows. Nottingham University Press, Nottingham.

Thornley JHM and France J 2006. Mathematical models in agriculture: quantitative methods for the plant, animal and ecological sciences, Second edition. $C A B$ International, Wallingford.

Uden P, Colucci PE and Van Soest PJ 1980. Investigation of chromium, cerium and cobalt as markers in digesta. Journal of Science of Food and Agriculture 31, 625-632.

Valk H, Keusink-Kappers IE and Van Vuuren AM 2000. Effect of reducing nitrogen fertilizer on grassland on grass intake, digestibility and milk production of dairy cows. Livestock Production Science 63, 27-38.

Van Es AJH 1975. Feed evaluation for dairy cows. Livestock Production Science 2, 95-107.

VandeHaar MJ and St-Pierre N 2006. Major advances in nutrition: relevance to the sustainability of the dairy industry. Journal of Dairy Science 89, 1280-1291.

Van Knegsel ATM, Van den Brand H, Dijkstra J, Tamminga S and Kemp B 2005. Effect of dietary energy source on energy balance, production, metabolic disorders and reproduction in lactating dairy cattle. Reproduction Nutrition Development 45, 665-688.

Van Knegsel ATM, Van den Brand H, Dijkstra J, Tamminga S and Kemp B 2006. Effect of dietary energy source on energy partitioning in dairy cattle in early lactation. Journal of Animal Science 84, (suppl 1)/Journal of Dairy Science 89, (suppl 1) 267.

Volden H, Mydland LT and Olaisen V 2002. Apparent ruminal degradation and rumen escape of soluble nitrogen fractions in grass and grass silage 
administered intraruminally to lactating dairy cows. Journal of Animal Science 80, 2704-2716.

Weimer PJ 1992. Cellulose degradation by ruminal microorganisms. Critical Reviews in Biotechnology 12, 189-223.

Williams BA, Oostdam AJ, Groot JCJ, Boer H and Tamminga S 2000. Effects of ageing on the in vitro fermentation of cell walls and cell contents of entire, fractionated and composite leaves of Italian ryegrass. Journal of Science of Food and Agriculture 80, 484-490.

Yang H-J, Tamminga S, Williams BA, Dijkstra J and Boer H 2005. In vitro gas and volatile fatty acids production profiles of barley and maize and their soluble and washout fractions after feed processing. Animal Feed Science and Technology 120, 125-140. 